\title{
Co-delivery of ciprofloxacin and colistin using microcontainers for bacterial biofilm treatment
}

Birk, Stine Egebro; Mazzoni, Chiara; Mobasharah Javed, Madeeha; Borre Hansen, Morten; Krogh Johansen, Helle; Anders Juul Haagensen, Janus; Molin, Søren; Hagner Nielsen, Line; Boisen, Anja

Published in:

International Journal of Pharmaceutics

Link to article, DOI:

10.1016/j.ijpharm.2021.120420

Publication date:

2021

Document Version

Peer reviewed version

Link back to DTU Orbit

Citation (APA):

Birk, S. E., Mazzoni, C., Mobasharah Javed, M., Borre Hansen, M., Krogh Johansen, H., Anders Juul Haagensen, J., Molin, S., Hagner Nielsen, L., \& Boisen, A. (2021). Co-delivery of ciprofloxacin and colistin using microcontainers for bacterial biofilm treatment. International Journal of Pharmaceutics, 599, [120420]. https://doi.org/10.1016/j.ijpharm.2021.120420

\section{General rights}

Copyright and moral rights for the publications made accessible in the public portal are retained by the authors and/or other copyright owners and it is a condition of accessing publications that users recognise and abide by the legal requirements associated with these rights.

- Users may download and print one copy of any publication from the public portal for the purpose of private study or research.

- You may not further distribute the material or use it for any profit-making activity or commercial gain

- You may freely distribute the URL identifying the publication in the public portal 


\section{Co-delivery of ciprofloxacin and colistin using microcontainers}

2 for bacterial biofilm treatment

3 Stine Egebro Birk ${ }^{a^{*}}$, Chiara Mazzoni ${ }^{a}$, Madeeha Mobasharah Javed ${ }^{a}$, Morten Borre Hansen ${ }^{b}$, Helle Krogh Johansen $^{d, e}$, Janus Anders Juul Haagensen ${ }^{c}$, Søren Molin ${ }^{c}$, Line Hagner Nielsen ${ }^{a}$ and Anja Boisen ${ }^{a}$

5

6

aThe Danish National Research Foundation and Villum Foundation's Center for Intelligent Drug Delivery and Sensing Using Microcontainers and Nanomechanics (IDUN), Department of Health Technology, Technical University of Denmark, Ørsteds Plads 345C, 2800 Kongens Lyngby, Denmark

${ }^{b}$ Novo Nordisk Foundation Center for Intestinal Absorption and Transport of Biopharmaceuticals, Department of Health Technology, Technical University of Denmark, Produktionstorvet 423, 2800 Kongens Lyngby, Denmark

'Novo Nordisk Foundation Center for Biosustainability, Technical University of Denmark, Kemitorvet 220, 2800 Kongens Lyngby, Denmark

${ }^{\mathrm{d} D e p a r t m e n t}$ of Clinical Microbiology, Section 9301 Copenhagen University Hospital Rigshospitalet, Henrik Harpestrengs Vej 4A, Copenhagen $\varnothing 2100$, Denmark

eDepartment of Clinical Medicine Faculty of Health and Medical Sciences University of Copenhagen, Blegdamsvej 3B, Copenhagen N 2200, Denmark

\section{"Corresponding author}

Stine Egebro Birk

$\emptyset$ rsteds Plads 345C

2800 Lyngby

stegha@dtu.dk

+4528450197 


\section{Graphical abstract}

44

\section{Abstract} 2

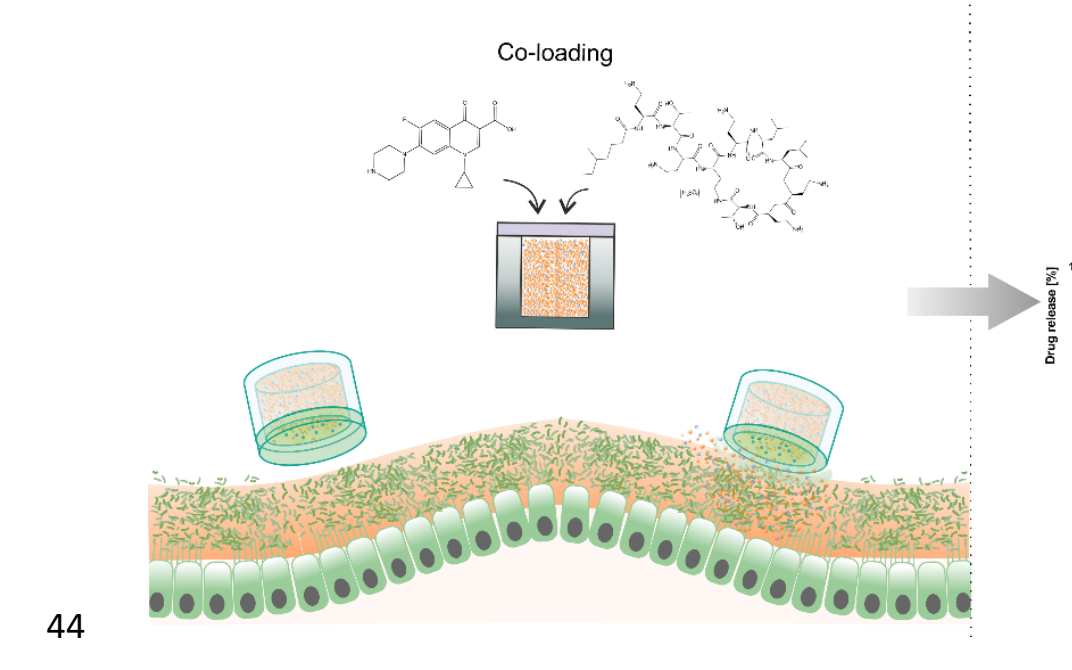

In many infected patients, bacterial biofilms represent a mode of growth that significantly enhances the tolerance to antimicrobials, leaving the patients with difficult-to-cure infections. Therefore, there is a growing need for effective treatment strategies to combat biofilm infections. In this work, reservoirbased microdevices, also known as microcontainers (MCs), are co-loaded with two antibiotics: ciprofloxacin hydrochloride (CIP) and colistin sulfate (COL), targeting both metabolically active and dormant subpopulations of the biofilm. We assess the synergistic effect of the two drugs in a time-kill study of planktonic $P$. aeruginosa and find that co-loaded MCs are superior to monotherapy, resulting in complete killing of the entire population. Biofilm consortia of $P$. aeruginosa grown in flow chambers were not fully eradicated. However, antibiotics in MCs work significantly faster than simple perfusion of antibiotics ( $62.5 \pm 8.3 \%$ versus $10.6 \pm 10.1 \%$ after $5 \mathrm{~h}$ ) in biofilm consortia, showing the potential of the MC-based treatment to minimize the use of antimicrobials in future therapies.

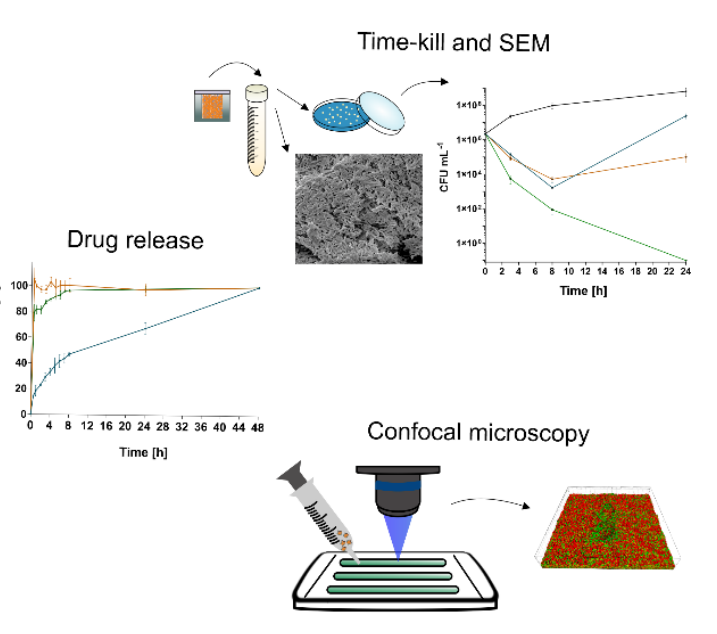




\section{Introduction}

Antibiotic resistance is one of the greatest challenges facing the global healthcare system (Davies and Davies, 2010). Microbes are developing resistance at an alarming rate, while the 'golden era' of antibiotic discovery is long over (O'Neill, 2016). This leaves us with a clear demand for novel strategies to combat multi-drug resistant (MDR) bacterial infections (Parish, 2019). Besides from MDR, it has become evident that the ability of bacteria to organize themselves into matrixenclosed aggregates, also known as biofilm, is responsible for most chronic bacterial infections (HallStoodley et al., 2004). In fact, it has been shown that the biofilm-lifestyle renders the bacteria with a 101,000-fold higher tolerance towards antibiotics than their planktonic counterparts (Mah and O'Toole, 2001; Stewart, 2002). Gradients of nutrients and oxygen exist from the top to the bottom of the biofilm, with oxygen levels being high at the surface and low in the center of the biofilm. Similarly, metabolic activity is stratified with high activity at the surface and low or no growth in the center (Ciofu and TolkerNielsen, 2019; Pamp et al., 2008). As the antimicrobial effect of antibiotics often depends on the metabolic activity of the bacteria, this dormancy-phenomenon is one of the explanations for the reduced susceptibility of biofilm-associated bacteria towards antibiotics (Høiby et al., 2010). Consequently, monotherapy with antibiotics, which are only active against growing cells, leads to a reduction of bacteria without complete eradiation of the biofilm (Anwar and Costerton, 1990).

Combining antibiotics with different cellular targets is widely recognized as a useful strategy to increase the likelihood of achieving early adequate bacterial eradication of infections, where monotherapy has failed, and at the same time minimizing the risk of resistance development (Tamma et al., 2012; Traugott et al., 2011). Ciprofloxacin is a fluoroquinolone antibiotic showing broad activity mainly against Gramnegative bacteria, such as Pseudomonas aeruginosa that are associated with debilitating infections in the airways (Bjarnsholt, 2011; Schwerdt et al., 2018) and wounds (Pastar et al., 2013). Ciprofloxacin exhibits bacteriostatic and bactericidal effects by inhibiting the DNA gyrase and topoisomerase IV enzymes essential for DNA replication (Aldred et al., 2014; Silva et al., 2011), thus targeting mainly the actively dividing cells found in the outer edges of the biofilm (Høiby et al., 2010). The cyclic cationic lipopeptide, colistin, belonging to the family of polymyxins, has recently received raising attention because of its significant effect on MDR Gram-negative bacteria (Li et al., 2006; Nation et al., 2015). Colistin binds to the lipid A component in lipopolysaccharides disordering the cell membrane structure, making it more permeable (a detergent-like effect), which ultimately results in cellular death (Bialvaei and Samadi Kafil, 2015). This means that colistin kills dormant bacterial subpopulations found in the core of the biofilm (Haagensen et al., 2007; Pamp et al., 2008). The use of colistin was originally hampered due to its serious nephrotoxicity, but the limited therapeutic options have driven its revival as a last line of defense against severe $P$. aeruginosa infections ( $\mathrm{Li}$ et al., 2006). Colistin has shown attractive synergistic antimicrobial activity against $P$. aeruginosa when combined with antibiotics such as azithromycin (Lin et al., 2015), rifampicin (Giamarellos-Bourboulis et al., 2003), and ciprofloxacin (Buyck et al., 2015). 
Recently it was documented that liposomes co-loaded with ciprofloxacin and colistin showed an increase in of the antimicrobial efficacy against $P$. aeruginosa compared to monotherapies, while, at the same time, showing no toxicity towards the pulmonary epithelial cells (Chai et al., 2019; Wang et al., 2018; Yu et al., 2020). Liposomes are one example of a particulated drug delivery system, which are gaining considerable attention to improve the therapeutic efficacy of antibiotic treatments (Gao et al., 2018). By using particulates to deliver antibiotics, a sufficiently high drug concentration can be achieved at the site of infection, while reducing the administered dose, keeping systemic toxicity at a minimum as well as limiting the risk of development of resistance (Liu et al., 2019). However, many of these formulations suffer from poor drug loading capabilities as well as from restrictions concerning which drugs that can be encapsulated into the particles.

Recent and promising approaches have focused on reservoir-based polymeric microdevices serving as drug carriers for oral drug delivery (Nielsen et al., 2018). The microdevices have shown a promising potential towards prolonging the retention of drugs at the site of absorption as well as providing a higher local drug concentration (Ainslie et al., 2009; Chirra et al., 2014; Nielsen et al., 2016). Previously, we have proposed microcontainers (MCs), which are polymeric cylindrical structures, as a means to deliver high loads of antibiotics to the site of infection (Birk et al., 2020). Compared to other drug delivery systems, such as liposomes, the MCs possess the unique capability of allowing delivery of any antibiotic no matter the size, charge or lipo-/hydrophilicity. Therefore, the ratio between co-loaded antibiotics can easily be adjusted as desired. Moreover, MCs have demonstrated mucoadhesive properties as they can embed and engulf in mucus (a habitat which biofilms reside in) (Dalskov Mosgaard et al., 2019; Mazzoni et al., 2017; Nielsen et al., 2016). Moreover, adhesion was shown to be further promoted by coating the MCs with a lid of chitosan (Mazzoni et al., 2019). Previously we have shown that local delivery of ciprofloxacin hydrochloride (CIP) confined in MCs resulted in eradication of $P$. aeruginosa biofilm equal to a constant flow of an about three times higher concentration of the solubilized antibiotic. However, 10-20\% of the biomass remained alive despite treatment with CIP (Birk et al., 2020).

The aim of the present study was to exploit the potential of using MCs for co-delivery of synergistic antibiotics as a more efficient treatment of $P$. aeruginosa biofilms compared to monotherapies. CIP and colistin sulfate (COL) were co-loaded in MCs and coated with a mucoadhesive coating of chitosan. In vitro release kinetics were characterized together with time-kill investigations of planktonic $P$. aeruginosa and compared to antibiotic monotherapy. Lastly, the impacts of co-loaded MCs were investigated on biofilm consortia of $P$. aeruginosa and compared to single-loaded MCs and simple antibiotic perfusion. 


\section{Materials and Methods}

118

119

120

121

122

123

124

125

126

127

128

129

130

131

132

133

134

135

136

137

138

139

140

141

142

143

144

145

146

147

148

149

150

151

152

153

\subsection{Materials}

Silicon (Si) wafers (4" (100) n-type) were acquired from Okmetic (Vantaa, Finland), while the SU-8 constituents (SU-8 2075 and SU-8 Developer) were purchased from Micro Resist Technology (Berlin, Germany). Ciprofloxacin $\mathrm{HCl}$ (CIP) was from Fagron (Uitgeest, The Netherlands), while colistin sulfate (COL), chitosan (low MW 50-190 kDa, 75-85 \% deacetylation), acetic acid, Luria Bertani (LB) medium, potassium phosphate, disodium phosphate, sodium chloride, calcium chloride, ammonium sulfate, magnesium chloride, trace metals, glucose, propidium iodide and glutaraldehyde ( $25 \%$ solution) were all bought from Sigma-Aldrich (St. Louis, MO USA). Osmium tetroxide (4 \% in water) was acquired from ACROS Organics. Ultrapure water was obtained from a $Q-P O D^{\circledR}$ dispenser (Merck Millipore, Burlington, MA, USA).

\subsection{Fabrication of MCs}

MCs were fabricated on silicon wafers using a mask-based two-step photolithography process, an approach originally introduced for drug delivery devices by Tao et al. and later modified by Nielsen et al. (Nielsen et al., 2012; Tao et al., 2007). Starting out with clean Si substrates, a release layer consisting of $5 \mathrm{~nm}$ titanium ( $\mathrm{Ti}$ ) and $20 \mathrm{~nm}$ gold ( $\mathrm{Au}$ ) was deposited (Temescal FC-2000, Ferrotec Corporation, Santa Clara, CA, USA) using electron beam evaporation. The release layer ensured adequate adhesion of the MCs to the chip during loading and coating, while simultaneously enabling the detachment of MCs from the chip without damaging them (Nielsen et al., 2016). Subsequently, the Ti/Au-Si wafers were covered with a layer of the negative epoxy photoresist SU-8 and exposed to a number of baking steps allowing the formation of the bottom and the side walls of the MCs. After fabrication, the wafers were diced (Automatic Dicing Saw DAD 321, DISCO, Tokyo, Japan) into squared chips $\left(12.8 \times 12.8 \mathrm{~mm}^{2}\right)$, with each chip containing 625 individual MCs. The inner and outer diameters of the individual MCs were determined with an Eclipse L200 bright-field optical microscope (Nikon, Tokyo, Japan), whereas the inner and outer heights were evaluated by vertical scanning interferometry using a PLu Neox 3D Optical Profiler (Sensofar, Terrassa, Spain).

\subsection{Loading of CIP and COL into MCs and coating with chitosan}

Prior to drug loading, a shadow mask was aligned on top of the chip containing MCs in order to minimize the amount of drug powder being distributed into the gaps between the MCs, as previously described (Abid et al., 2017).

For the co-loading, CIP and COL powders were mixed in a 1:8 w/w ratio. CIP:COL or pure COL powder was loaded into MCs using a centrifuge method previously described (Jørgensen et al., 2019). In brief, the powder was distributed on top of the mask and the chip was subsequently centrifuged in a flatbottomed Falcon tube using a Heraeus Megafuge 16R Centrifuge (Thermo Fisher Scientific, Waltham, MA, USA) at $3720 \mathrm{~g}$ for $120 \mathrm{~s}$ at room temperature. Following this, the chip was removed from the Falcon tube and additional powder was embossed into the cavity of the MCs by applying a pressure of $0.49 \cdot 10^{-}$

${ }^{1}$ Torr for $15 \mathrm{~s}$ with a compact digital pressure controlled electric crimper-MSK-160E (MTI Corporation, 
Richmond, CA, USA). The centrifugation and compression steps were conducted twice to ensure adequate drug loading. Afterwards, the shadow mask was removed and any excess drug around the MCs was gently removed using pressurized air. CIP was loaded into the MCs using only compression. The chips were weighed before and after loading to quantify the amount of loaded drug. Drug loading capacity was calculated as the amount of loaded drug relative to the weight of a drug-loaded MC. CIP:COL- and COL-loaded chips were stored in the freezer at $-18{ }^{\circ} \mathrm{C}$ until usage to ensure drug stability, whereas CIP-loaded chips were stored at room temperature.

Functionalization of the drug-loaded MCs was achieved by spray coating a lid of a chitosan solution over the chip using an Exacta Coat Ultrasonic Spray System (Sonotek, USA) with an accumist nozzle operating at $120 \mathrm{kHz}$. The chitosan solution was prepared by dissolving $0.5 \% \mathrm{w} / \mathrm{v}$ chitosan in $0.1 \mathrm{M}$ acetic acid, heated overnight at $50^{\circ} \mathrm{C}$ and subsequently, filtered using a 5-13 $\mu \mathrm{m}$ filter with vacuum suction. Each chip was coated with two alternating spray paths having an offset of $2 \mathrm{~mm}$, resulting in a total of 90 passages for CIP:COL and COL, and 120 passages for CIP. To facilitate solvent evaporation, the plate underneath the chip was heated to $50^{\circ} \mathrm{C}$. Generator power was kept at $1.3 \mathrm{~W}$, path speed at $25 \mathrm{~mm} / \mathrm{s}$ and infusion rate at $0.1 \mathrm{~mL} / \mathrm{min}$. The applied shaping air pressure was 0.020 bar for CIP:COL and for COL MCs, and 0.028 bar for CIP-loaded MCs. The distance between the spray nozzle and the sample was set to $5.5 \mathrm{~cm}$.

The quality of the loading and the coating of the MCs was evaluated using a tabletop scanning electron microscope (SEM) (Hitachi High-Technologies Europe GmbH, Krefeld, Germany). The MC chips were placed on a $30^{\circ}$ tilted holder and SEM images were acquired using the scattered electron (SE) detector and an accelerating voltage of $15 \mathrm{kV}$.

\subsection{Characterization of in vitro drug release from MCs using LC-MS}

The in vitro release from co-loaded MCs was investigated using liquid chromatography-mass spectrometry (LC-MS), and the MCs loaded with either CIP or COL were utilized as controls. A chip containing 625 MCs was diced into mini-chips containing 100-110 MCs using a diamond cutter. The minichip was placed in a Falcon ${ }^{\mathrm{TM}}$ tube containing $5 \mathrm{~mL}$ FAB medium (buffered minimal medium used for bacterial growth; for preparation see Supp. Materials, Table S1) at $100 \mathrm{rpm}$ and $37^{\circ} \mathrm{C}$. Samples of 200 $\mu \mathrm{L}$ were taken at specified time points over the course of $48 \mathrm{~h}$ and replaced with $200 \mu \mathrm{L}$ blank $\mathrm{FAB}$ medium. Samples with drug concentrations above the upper limit of detection for the LC-MS assay were diluted with FAB medium as appropriate. All samples were stored at $-18^{\circ} \mathrm{C}$ prior to the analysis.

Standards (0-50 $\mu \mathrm{M}$ CIP or COL) and samples were analyzed with a Shimadzu Nexera X2/Prominence HPLC (Shimadzu Europe, Duisburg, Germany) and ESI micrOTOF-Q III (Bruker Daltonics, Bremen, Germany) LC-MS setup. The LC was performed by a $5 \mu \mathrm{L}$ injection of the analyte on a Poroshell $120 \mathrm{SB}-$ C8 column, $2.7 \mu \mathrm{m}, 2.1 \times 50 \mathrm{~mm}$ (Agilent, Santa Clara, CA, USA) followed by elution with a linear gradient of $\mathrm{MeCN}$ and $2.5 \mathrm{mM} \mathrm{NH}_{4} \mathrm{OH}$ in water with $0.1 \%$ formic acid (from 0 to $100 \%$ over $9 \mathrm{~min}$ ) at a flow rate of $0.4 \mathrm{~mL} / \mathrm{min}$. The chromatographic front $(1.75 \mathrm{~min}$ ) was diverted to waste, while the remaining run was injected into the ESI micrOTOF-Q III mass spectrometer. A calibration solution consisting of $2.5 \mathrm{mM}$ 
$192 \mathrm{NaOH}, 2.25 \mathrm{mM}$ formic acid in $90 \% \mathrm{i}-\mathrm{PrOH} /$ water was injected into the ion source between 1.75 and

$1931.85 \mathrm{~min}$ at a flowrate of $30 \mu \mathrm{L} / \mathrm{h}$ for internal calibration of the spectra. MS analysis was performed in 194 positive mode in the range of $50-3,000 \mathrm{~m} / \mathrm{z}$ at a rate of $2 \mathrm{~Hz}$. For COL, a capillary potential of 5,000 V 195 was employed, the nebulization pressure was 1.5 bar and the drying gas flow was set to $3 \mathrm{~L} / \mathrm{min}$ at $180^{\circ} \mathrm{C}$. 196 For CIP, the parameters were 4,500 V, 0.3 bar and $4 \mathrm{~L} / \mathrm{min}$ at $200^{\circ} \mathrm{C}$. All mass spectra were analyzed with 197 the software QuantAnalysis (Bruker Daltonics, Bremen, Germany) to generate extracted ion 198 chromatograms for $332.16 \pm 0.05 \mathrm{~m} / \mathrm{z}$ (for CIP) and $1155.7 \pm 0.1 \mathrm{~m} / \mathrm{z}$ (for COL) and the resulting peaks were 199 integrated.

200 All experiments were carried out in 3-6 replicates and data were normalized to $100 \%$ in relation to the 201 measured amount of drug release after $48 \mathrm{~h}$.

\section{2.5. Bacterial strains and overnight culturing}

203 For all bacterial studies, a P. aeruginosa PAO1 strain (Klockgether et al., 2010) genetically modified to 204 express green fluorescent protein (GFP) constitutively by insertion into a neutral intergenic region in the 205 genome was used (Holloway and Morgan, 1986; Klausen et al., 2003; Stover et al., 2000). Overnight 206 cultures of PAO1 were grown in lysogeny broth (LB) at $150 \mathrm{rpm}$ at $37^{\circ} \mathrm{C}$ for $18-20 \mathrm{~h}$.

\section{2.6. Time-kill studies of planktonic $P$. aeruginosa using co-loaded MCs}

208 For studying the ability of co-loaded MCs to inhibit bacterial growth, an inoculation of PAO1 overnight 209 culture was diluted to a final concentration of approximately $1 \times 10^{6}$ cells $/ \mathrm{mL}$. As controls, single loaded 210 MCs were used in the same set-up. To each vial containing $10 \mathrm{~mL}$ culture, treatment was added as either 211 uncoated MCs, coated MCs or antibiotic solution (for concentrations see Figure 1). PAO1 in LB without 212 treatment and pure LB were used as negative control. The number of added MCs varied according to 213 the difference in antibiotic loading per MC (determined per individual chip) and the minimum inhibitory 214 concentration (MIC) values of the antibiotics (aiming for reaching $4 \times \mathrm{MIC}$ for each antibiotic). Vials were 215 stored at $150 \mathrm{rpm}$ and $37^{\circ} \mathrm{C}$ during the course of the experiment. Samples were taken at $0,3,8$ and 24 $216 \mathrm{~h}$, and viable counts were obtained by serial dilution followed by spot plating on LB agar plates. The 217 plates were left to incubate overnight at $37{ }^{\circ} \mathrm{C}$ and colony forming units (CFU) were counted the 218 following day. 


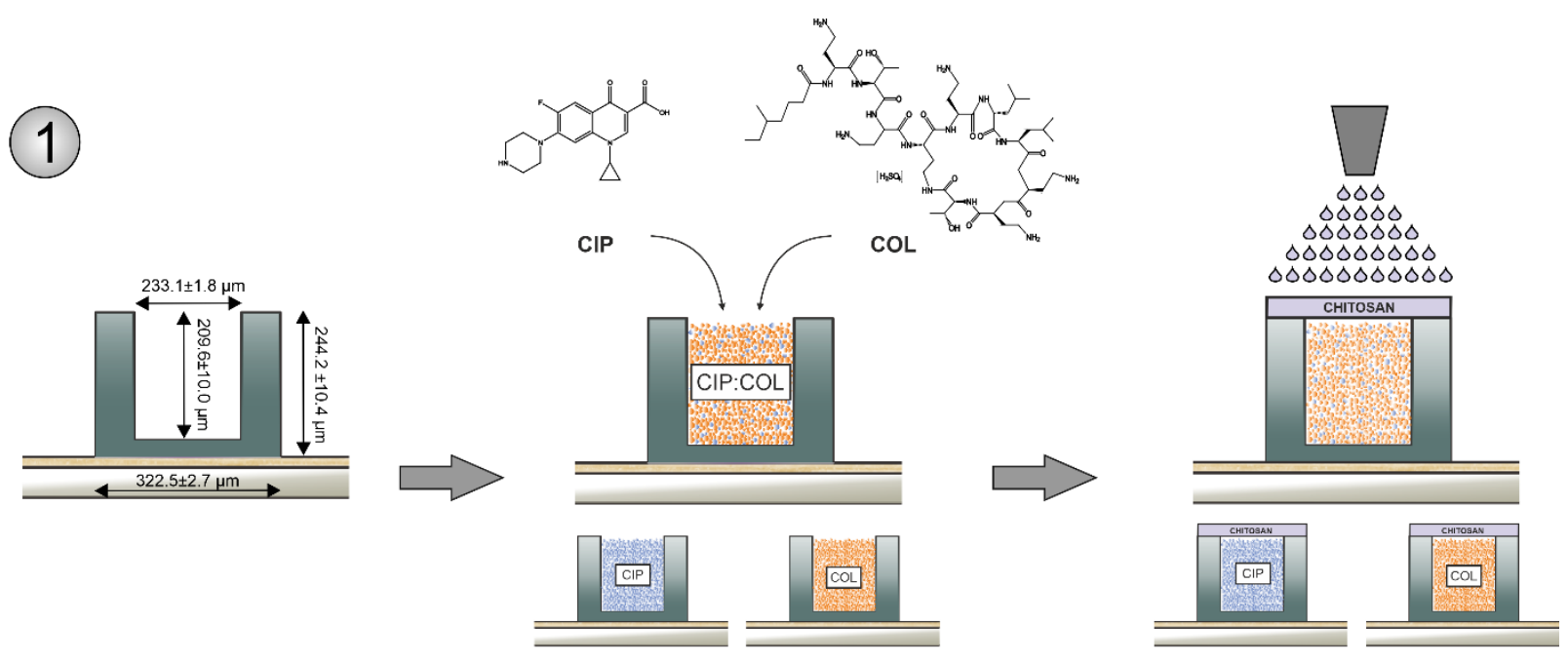

(2)

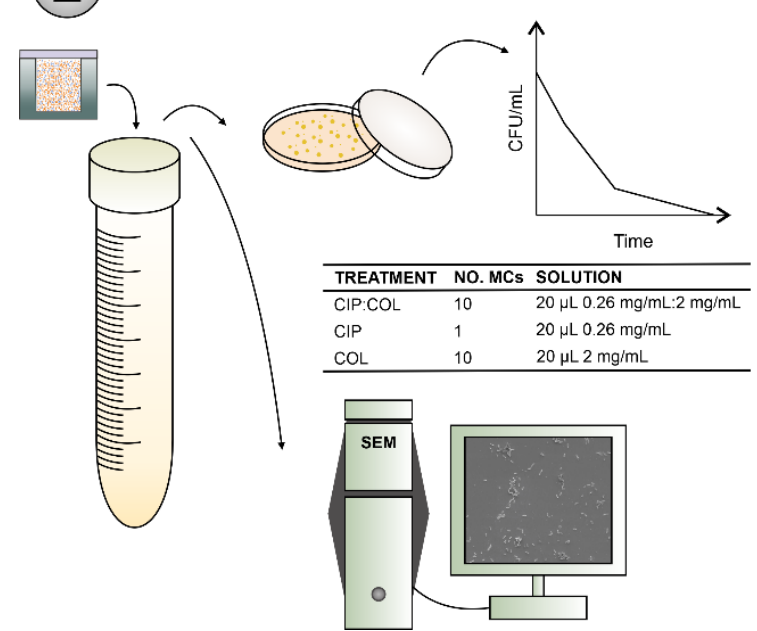

3

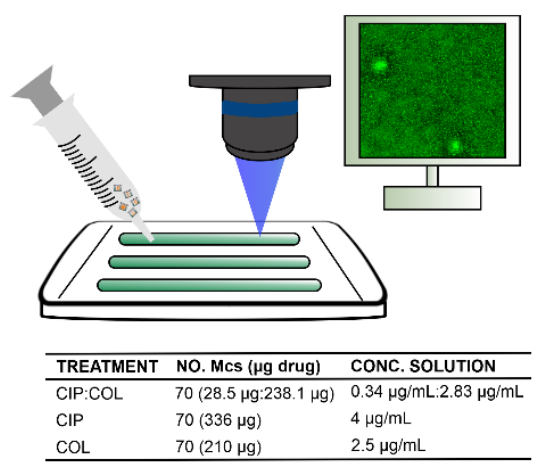

Figure 1. Schematic presentation of the production of microcontainers (MCS) and the conducted experiments on $P$. aeruginosa PAO1. 1) Dimensions of fabricated MCs (mean $\pm S D, n=6-12$ ), co-loading or single-loading of ciprofloxacin hydrochloride (CIP) and/or colistin sulfate (COL) followed by coating with chitosan. 2) MCs were tested against PAO1 cultures in shaken LB medium. Samples were taken over time for counting the colony forming units (CFU/mL). MCs were tested both with and without chitosan coating and compared to treatment with antibiotic in solution. See table for applied concentrations. Scanning electron microscopy (SEM) was applied as a visual assessment of bacterial killing after $24 \mathrm{~h}$. 3) MCs were tested against PAO1 in biofilm mode of growth using flow-chambers and with confocal microscopy monitoring. See table for applied concentrations.

\subsection{SEM observation of $P$. aeruginosa cells post treatment with MCs}

A qualitative study was performed to investigate the ability of the coated CIP:COL, CIP or COL MCs to inhibit biofilm formation on glass slides over $24 \mathrm{~h}$. Microscopic glass slides were cut into smaller rectangles of approximately $3 \times 7 \mathrm{~mm}$ size using a diamond cutter. The glass slides were sterilized in ethanol for $20 \mathrm{~min}$, left to air dry and subsequently, mounted onto vials with Pressure Sensitive Adhesive (PSA) tape. Growth and treatment were conducted as described in Section 2.6.

Sample fixation was completed as previously described by Weber et al. (Weber et al., 2014). In brief, the samples were covered with $2.5 \%$ glutaraldehyde for $2 \mathrm{~h}$, washed three times in phosphate buffered saline (PBS) and then transferred to wells containing $0.5 \mathrm{~mL} 1 \%$ osmium tetroxide for $1 \mathrm{~h}$. Thereafter, 
the samples were dehydrated in solutions with increasing ethanol percentages (35\%, $50 \%, 75 \%$, 2x90 $\%$, and $2 \times 100 \%$ ) for $30 \mathrm{~min}$ in each solution. After the last dehydration step, the samples were placed in a critical point dryer (Leica EM CPD300 Critical point dryer, Germany) for $2 \mathrm{~h}$ to allow further dehydration of the sample without causing structural changes to the bacteria. Lastly, the samples were placed in a desiccator overnight.

Prior to SEM analysis, the biofilm samples on glass slides were coated with a thin conducting layer of gold (Quorum Q150T ES Coater, Quorum Technologies, Lewes, United Kingdom) to prevent sample charging with the electron beam. Tooling factor was 2.3. Sputter current was kept at $20 \mathrm{~mA}$ and a sputter time of $65 \mathrm{~s}$ were used, whereas the clean current was $60 \mathrm{~mA}$ and clean time of $30 \mathrm{~s}$. The stage was rotating at a speed of $30 \mathrm{rpm}$. SEM images were acquired using a QFEG 200 Cryo-ESEM (FEI Company, USA) using the Everhart-Thornley (ETD) detector with high vacuum mode and a voltage of $5 \mathrm{kV}$.

\subsection{Growth of $P$. aeruginosa biofilms in flow chambers and treatment with antibiotics}

\subsubsection{Growth of PAO1 biofilms}

The PAO1 biofilm growth was conducted at $37^{\circ} \mathrm{C}$ under laminar flow in self-fabricated flow chambers. The flow chambers were fabricated by milling in a $6 \mathrm{~mm}$ thick sheet of polycarbonate as previously described (Tolker-Nielsen and Sternberg, 2011). Additionally, they were redesigned with an inlet channel on the side of the flow chamber to which a small piece of silicon tubing was glued, allowing for inoculation of MCs (Birk et al., 2020). A sterile system was achieved by pumping $1 \mathrm{~L}$ of $0.5 \% \mathrm{v} / \mathrm{v}$ hypochlorite through the system over a period of $4 \mathrm{~h}$ followed by a cleaning procedure with filling and emptying the system three times with $2 \mathrm{~L}$ of autoclaved MilliQ water. The system was perfused overnight with modified FAB minimal medium with trace metals (for preparation see Supp. Materials, Table S1) at $58.4 \mu \mathrm{L} / \mathrm{min}$ with a 16-channel Watson Marlow pump. The flow was stopped, and the tubings were clamped to avoid backflow and sterilized with $70 \% \mathrm{v} / \mathrm{v}$ ethanol on the outside. Thereafter, $250 \mu \mathrm{L}$ of a diluted overnight culture (with $0.9 \% \mathrm{NaCl}$ to $\mathrm{OD}_{600}$ of 0.05 ) was inoculated carefully into the flow chamber and resealed with silicone glue. Flow chambers were left without flow for $1 \mathrm{~h}$ to allow bacterial attachment to the glass surface, before medium flow was resumed. Bacterial biofilms were allowed to develop for $72 \mathrm{~h}$ before antibiotic treatment.

\subsubsection{Treatment with antibiotics}

Treatment with CIP and COL were conducted in two ways: I) as confined in coated MCs (either as coloaded or as single-loaded as controls), or II) as a constant perfusion. 70 MCs were added to each flow chamber, and constant perfusion was achieved by adding CIP and/or COL to the medium bottle (see Figure 1 for concentrations). To allow inoculation of MCs, a solution of $2.5 \% \mathrm{w} / \mathrm{v}$ gelatin (Sigma-Aldrich Chemie $\mathrm{GmbH}$, Steinheim, Germany) was used to disperse the microcontainer in the syringe instead of sticking to the walls of the syringe as described previously (Birk et al., 2020). Biofilms were treated for $24 \mathrm{~h}$, after which images were acquired at a distance of 140-320 $\mu \mathrm{m}$ from the open side of the MCs and in case of perfusion at random locations in the flow chamber. 


\subsubsection{Microscopy parameters, image acquisition and analysis}

Biofilms were monitored using an inverted Leica TCS SP8 CLSM (Mannheim, Germany) equipped with an argon/krypton laser and detectors and filter set for sequential monitoring of GFP (excitation wavelength: $488 \mathrm{~nm}$, emission range: $493-558 \mathrm{~nm}$ ) for live cell imaging and propidium iodide (excitation wavelength: $543 \mathrm{~nm}$, emission range: $558-700 \mathrm{~nm}$ ) for dead cell staining. Images were obtained in zintervals of $1 \mu \mathrm{m}$ using an HC PL Apo CS2 63x oil objective (numerical aperture 1.4). PAO1 expressed GFP consecutively, and propidium iodide had to be injected into the bubble trap. As control, four biological experiments were performed acquiring two images (technical replicates) of non-treated biofilm in each experiment at random positions within the flow chamber. For each treatment, 3-5 biological replicates with 3-5 technical replicates were acquired. Stacked images and 3D images were generated using Imaris software (Version 7.7.1, Bitplane AG, Zürich, Switzerland). Volume of biomass was calculated using the image analysis software COMSTAT version 2.1 (Heydorn et al., 2000; Vorregaard, 2008). Graphs depicting the fraction of live/dead biomass were generated by calculating the percentage of live/dead in relation to the total biomass measured at the specified time-point.

\subsection{Statistical analysis}

Data are expressed as the mean $\pm S D$, unless otherwise stated. For comparison of two individual mean values an unpaired t-test was applied, whereas a one-way ANOVA with Tukey's multiple comparison was used if more than two mean values were compared. Graphs and tests were conducted in GraphPad Prism (Version 8.0.1, GraphPad Software, CA, USA) and p-values were considered statistically significant when below $1 \%(p<0.01)$.

\section{Results and Discussion}

\subsection{Loading of antibiotics into MCs and coating depositing}

MCs were produced with good reproducibility in the desired dimensions (see Figure 1 for dimensions). For the co-loading of CIP:COL, we chose a $1: 8 \mathrm{w} / \mathrm{w}$ ratio based on the MIC values of the individual antibiotics towards PAO1 cells $(0.125 \mu \mathrm{g} / \mathrm{mL}$ for CIP (Soares et al., 2019); $1 \mu \mathrm{g} / \mathrm{mL}$ of COL (Bergen et al., 2010)). The loading resulted in $3.85 \pm 0.37 \mu \mathrm{g} / \mathrm{MC} \mathrm{CIP}: \mathrm{COL}, 5.16 \pm 0.54 \mu \mathrm{g} / \mathrm{MC}$ CIP or $3.32 \pm 0.57 \mu \mathrm{g} / \mathrm{MC} \mathrm{COL}$ $(n=12-18$, mean $\pm S D)$, corresponding to a drug loading capacity of $14.6-21.0 \% \mathrm{w} / \mathrm{w}$. Efficient loading was confirmed with SEM (Figure 2A and Supp. Materials, Figure S1). After drug loading, the cavity of the MCs was coated with a layer of chitosan, serving to promote bioadhesion. Moreover, chitosan is known to contribute to the killing of $P$. aeruginosa (Perinelli et al., 2018). The coating of CIP:COL- and COLloaded MCs resulted in a uniform, fully covering lid, whereas the coating of CIP-loaded MCs was less uniform, a tendency also previously observed (Birk et al., 2020) (Figure 2B and Supp. Materials, Figure S1). 

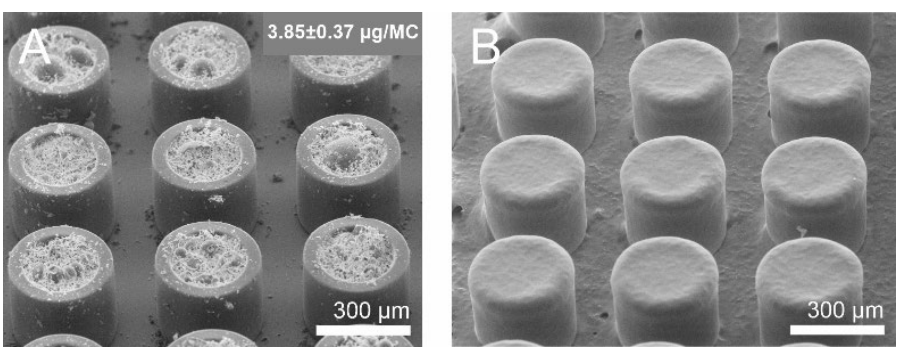

Figure 2. Scanning electron microscope (SEM) images of microcontainers (MCS) co-loaded with ciprofloxacin hydrochloride and colistin sulfate $(1: 8 \mathrm{w} / \mathrm{w})(\mathbf{A})$ and subsequently coated with chitosan (B). (1-column figure)

\subsection{In vitro drug release from MCs}

The release of $\mathrm{CIP}$ and/or $\mathrm{COL}$ from chitosan-coated MCs was evaluated at $37^{\circ} \mathrm{C}$ in $\mathrm{FAB}$ medium at pH 6.8 (Figure 3) (for release from uncoated MCs, see Supp. Materials Figure S2).

The co-loaded chitosan-coated MCs released their entire COL cargo within the first 30 min reaching a release of $98.7 \pm 5.7 \%$. This was similar to what was observed from the single-loaded COL MCs $(105.2 \pm 8.8 \%)$, and co-loading therefore did not influence the release profile of COL. The release of CIP was significantly accelerated from the co-loaded MCs (79.0 $\pm 6.4 \%$ within $30 \mathrm{~min})$ as compared to when CIP was single-loaded (13.8 $\pm 1.2 \%$ within $30 \mathrm{~min}$ ). This tendency was also observed in a previous study with liposomes, where incorporation of COL significantly accelerated the CIP release compared to liposomes loaded only with CIP (Wang et al., 2018). Sustained release from chitosan particles is a well-known phenomenon (Mohammed et al., 2017) and has previously been shown for CIP-loaded chitosan NPs (Patel et al., 2019) and CIP- or lysozyme loaded MCs (Birk et al., 2020; Mazzoni et al., 2019). The chitosan lid is shown to swell due to the hydrogel properties of chitosan (Ahmadi et al., 2015) creating pores which allows diffusion of CIP and COL. The diffusion rate depends on the hydrophilicity of the drugs, and the different release profiles can therefore be attributed to the higher aqueous solubility of COL (50 mg/ml (Wang et al., 2016)) compared to CIP (varying solubilities reported: 0.17-30 $\mathrm{mg} / \mathrm{mL}$ (Olivera et al., 2011; Ross and Riley, 1994; Varanda et al., 2006)). Moreover, it is well known that surfactants influence the degree of hydrogel swelling and can provide micellar solubilization of poorly water-soluble drugs (Gunathilake et al., 2018; Wallace et al., 2010). As COL is amphiphilic in nature, we believe that $\mathrm{COL}$ served as a surfactant, affecting the swelling of chitosan and the associated drug release. In the current study, $\mathrm{COL}$ constituted approximately $90 \%$ of the co-loaded $\mathrm{MC}$ (due to the large difference in MIC values of CIP and COL). Seemingly, the water soluble and fast-releasing COL drove the release of the otherwise less soluble CIP. 


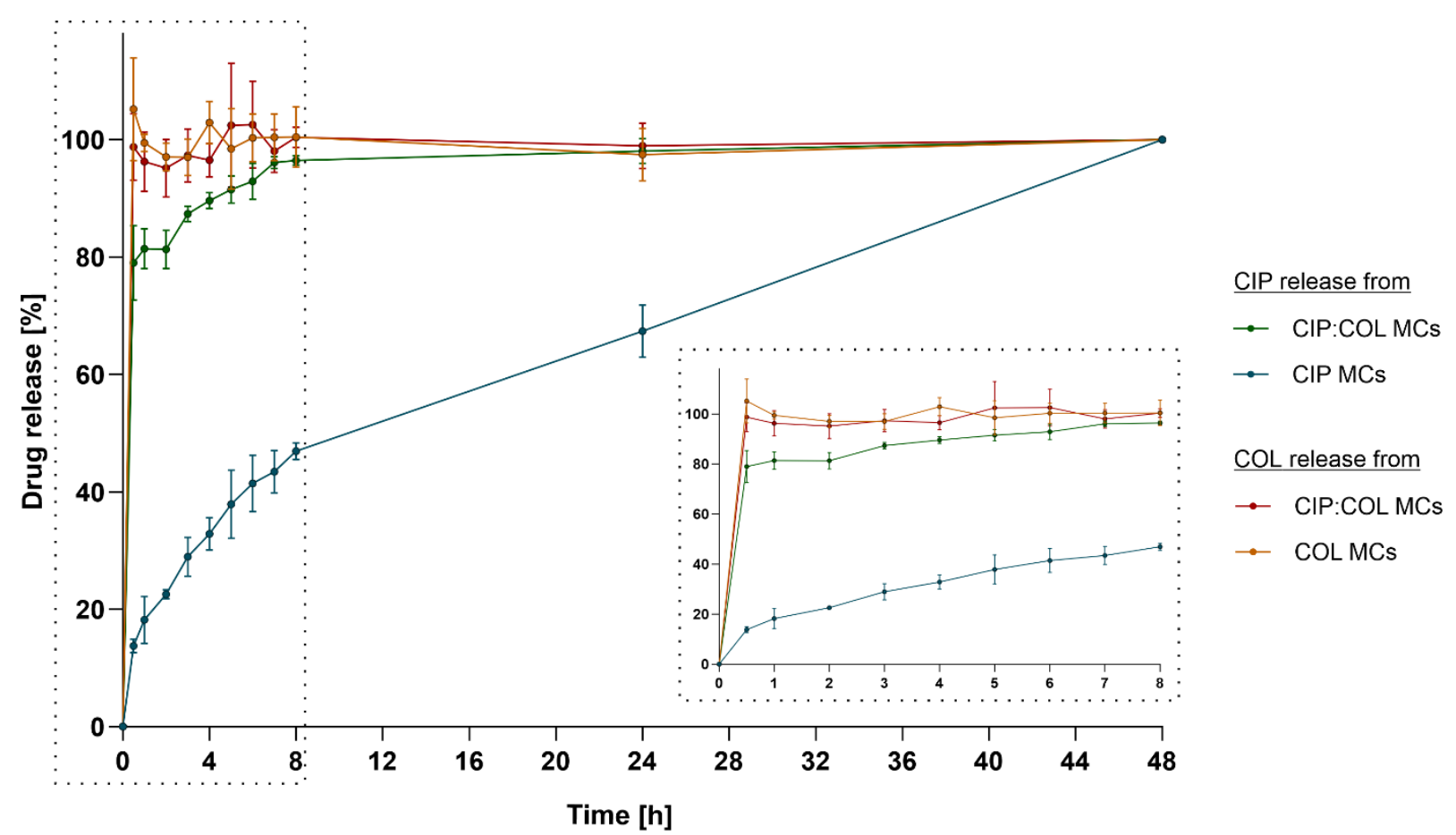

Figure 3. In vitro release of ciprofloxacin hydrochloride (CIP) and colistin sulfate (COL) from co-loaded or single-loaded microcontainers (MCs) coated with chitosan. Release study was performed at $37^{\circ} \mathrm{C}$ in $\mathrm{FAB}$ medium at $\mathrm{pH} 6.8$ and quantified by LC-MS. Data was normalized to $100 \%$ and presented as mean \pm SD, $n=3-4$. (2-column figure)

\subsection{Time-kill of planktonic $\boldsymbol{P}$. aeruginosa using co-loaded MCs}

The capabilities of the drug-loaded and coated MCs to inhibit and kill planktonic bacteria were investigated by adding MCs to a growing population of $P$. aeruginosa (Figure 4) (for effect of uncoated MCs, see Supp. Materials Figure S3). Treatment with CIP:COL, CIP or COL significantly reduced bacterial growth compared to the PAO1 growth control ( $p \leq 0.0001)$.

For co-loaded MCs, growth inhibition was increased compared to the monotherapies. The three types of treatments for the co-loaded MCs (uncoated, coated and solution) resulted in similar viable counts, which is in accordance with the rapid release of CIP:COL from the MCs (Figure 3 and Supp. Materials Figure S2). After $8 \mathrm{~h}$, no growth was observed except for the coated MCs (note: only 1 out of 4 replicates showed growth). At $24 \mathrm{~h}$, no growth was observed for any of the treatments.

When treating with CIP in MCs or in solution, the maximum killing was reached at $8 \mathrm{~h}$ and regrowth was observed at $24 \mathrm{~h}$, indicating a possible resistant subpopulation. No differences was observed between CIP in solution or confined in MCs throughout the $24 \mathrm{~h}$ period $(p \geq 0.36)$. Presumably, the starting bacterial density was sufficiently low to allow a similar inhibition despite the sustained release observed with the chitosan coating (Figure 3).

Similar reductions in viable counts were observed when treating with COL confined in MCs or in solution, which correlates with the release data showing that all COL was released within the first $30 \mathrm{~min}$. In contrast to CIP treatment, treating with COL generally did not give rise to a significant difference $(p \geq 0.02)$ between the viable counts after 3,8 , and $24 \mathrm{~h}$, thus indicating that the amount of $\mathrm{COL}$ was sufficient to prevent further regrowth. 
Altogether, the combination CIP:COL showed greater inhibition effect on PAO1 after $24 \mathrm{~h}$ compared to single-loaded MCs, a synergistic effect of the two antibiotics reaching levels where all subpopulations were killed with no regrowth. The synergistic mechanism of CIP and COL on planktonic cells is not yet completely understood, but may be attributed to the ability of COL to enhance the uptake of CIP by destabilizing the outer membrane of the Gram-negative bacterium (Buyck et al., 2015). Recently, Yu et al. treated two COL-resistant $P$. aeruginosa strains with $8 \mathrm{mg} / \mathrm{L} \mathrm{CIP}$ and $2 \mathrm{mg} / \mathrm{L} \mathrm{COL}$ delivered in a liposomal formulations and found an enhanced in vitro antimicrobial activity compared to the monotherapies (Yu et al., 2020). However, one strain showed regrowth after $24 \mathrm{~h}$ despite treating with the two antibiotics, whereas the other only showed a 2-log reduction. In our study (treating PAO1 with $0.5 \mathrm{mg} / \mathrm{L} \mathrm{CIP:} 4 \mathrm{mg} / \mathrm{L} \mathrm{COL}$ ), we observed a full eradication, and the difference may be attributed to the selection of the strain or the applied ratio of antibiotics.

370

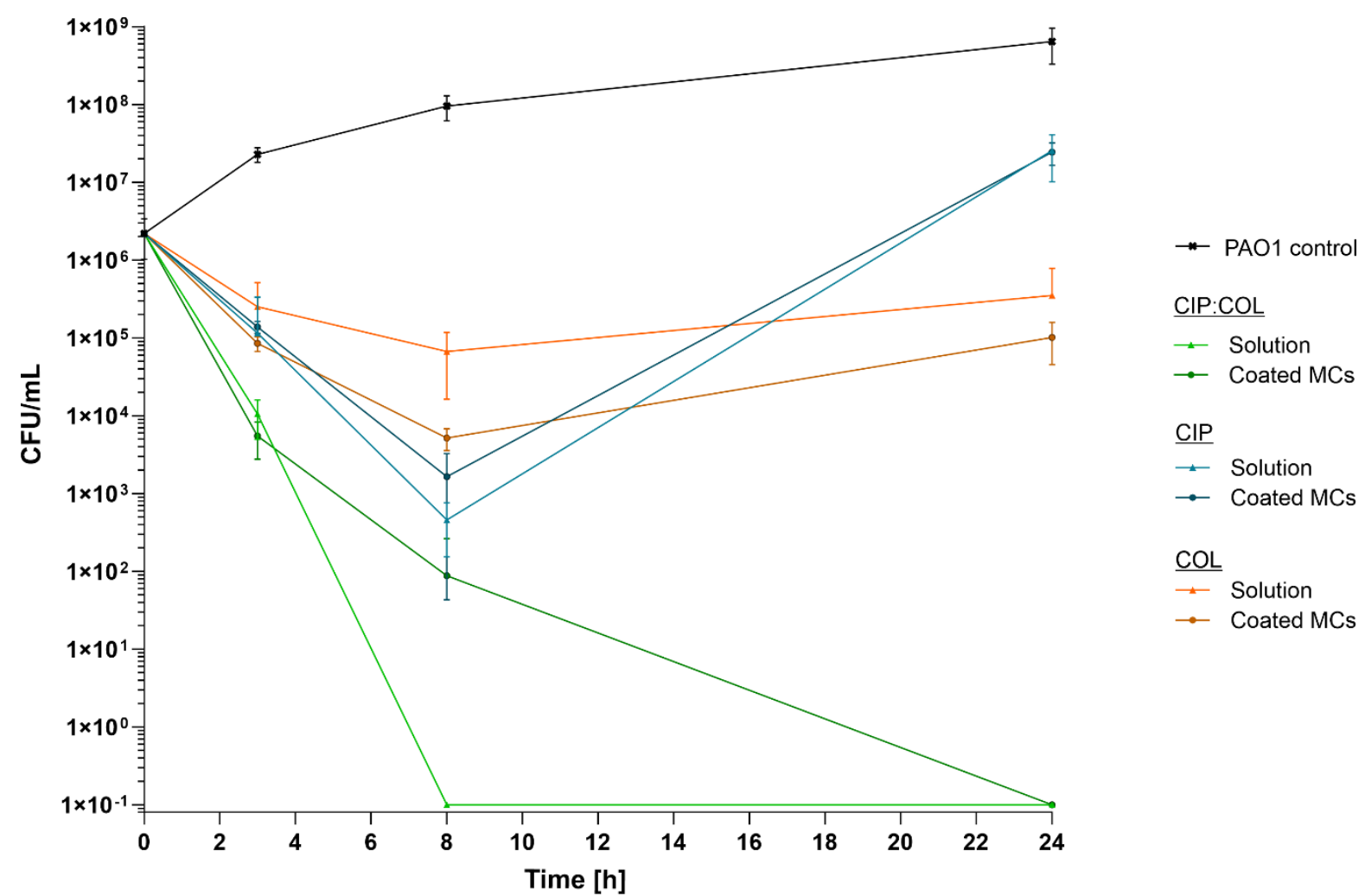

Figure 4. Inhibition of planktonic growth of $P$. aeruginosa (PAO1) over time when co-delivering ciprofloxacin hydrochloride (CIP) and colistin sulfate (COL) in chitosan-coated microcontainers (MCs) or as antibiotic solution. As controls, treatment with CIP or $\mathrm{COL}$ alone (as coated MCs or antibiotic solutions) as well as a positive control for PAO1 growth were included. Data is presented as mean $\pm \mathrm{SD}(\mathrm{n}=3-6)$. (2-column figure)

\subsection{SEM observation of $P$. aeruginosa cells post treatment with MCs}

SEM imaging of $P$. aeruginosa biofilms supported the viable counting results. Non-treated biofilms grew unevenly across the glass slide with certain areas containing huge and thick clusters (Figure 5A). These clusters were not found in the MC-treated samples, but instead single bacteria or small clusters were spread almost uniformly across the glass surface. However, the bacteria exposed to co-loaded and coated MCs were clearly affected by the treatment, and morphological changes appeared to correlate 
382 well with the mechanism of action of the individual antibiotics. For the co-loaded CIP:COL MCs, the 383 predominant effect on bacterial morphology originated from $\mathrm{COL}$ as cellular debris and deformed 384 bacteria were observed (Figure 5B), yet, single bacteria did also appear elongated as evident from the 385 zoom-in.

386 When the biofilm was treated with CIP-loaded MCs, the bacteria appeared elongated, which is in 387 accordance with the mechanism of CIP, inhibiting DNA replication and ultimately cellular division (Figure 388 5C) (Aldred et al., 2014). Also, the membrane disordering effect of COL (Bialvaei and Samadi Kafil, 2015) 389 was evident in the samples treated with COL-loaded MCs, as extracellular material could be observed in 390 between the bacteria (Figure 5D). Moreover, the cell length appeared to be diminished and the bacteria 391 to be collapsed. This is in accordance with previous results from the investigation of the effect of COL 392 on the cellular structure of $P$. aeruginosa using atomic force microscopy (Mortensen et al., 2009). They 393 observed that after only $3 \mathrm{~h}$ of $\mathrm{COL}$ treatment, the cells had almost completely lost their morphological 394 structure. The visual assessment after treatment with CIP:COL MCs revealed that COL had the biggest 395 impact on the bacteria, a tendency which is probably a consequence of two factors. Firstly, that the co396 loaded CIP:COL MCs contained significantly more COL than CIP, and secondly, that COL quickly 397 destabilizes the membrane thereby, evading the cellular elongation as otherwise observed after the 398 treatment with only CIP. 

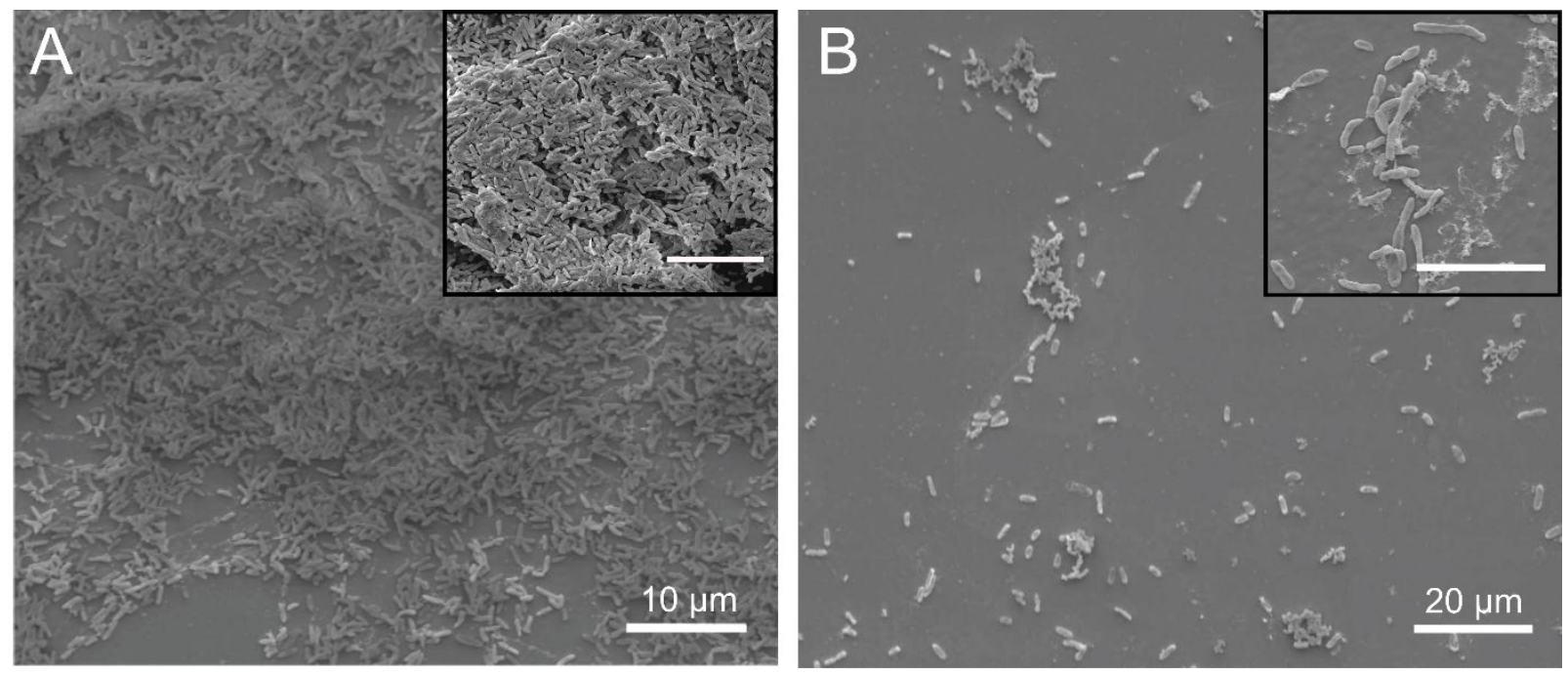

400

401

402

403

404

405

406

407

408

409

410

411

412

413

414

415

416
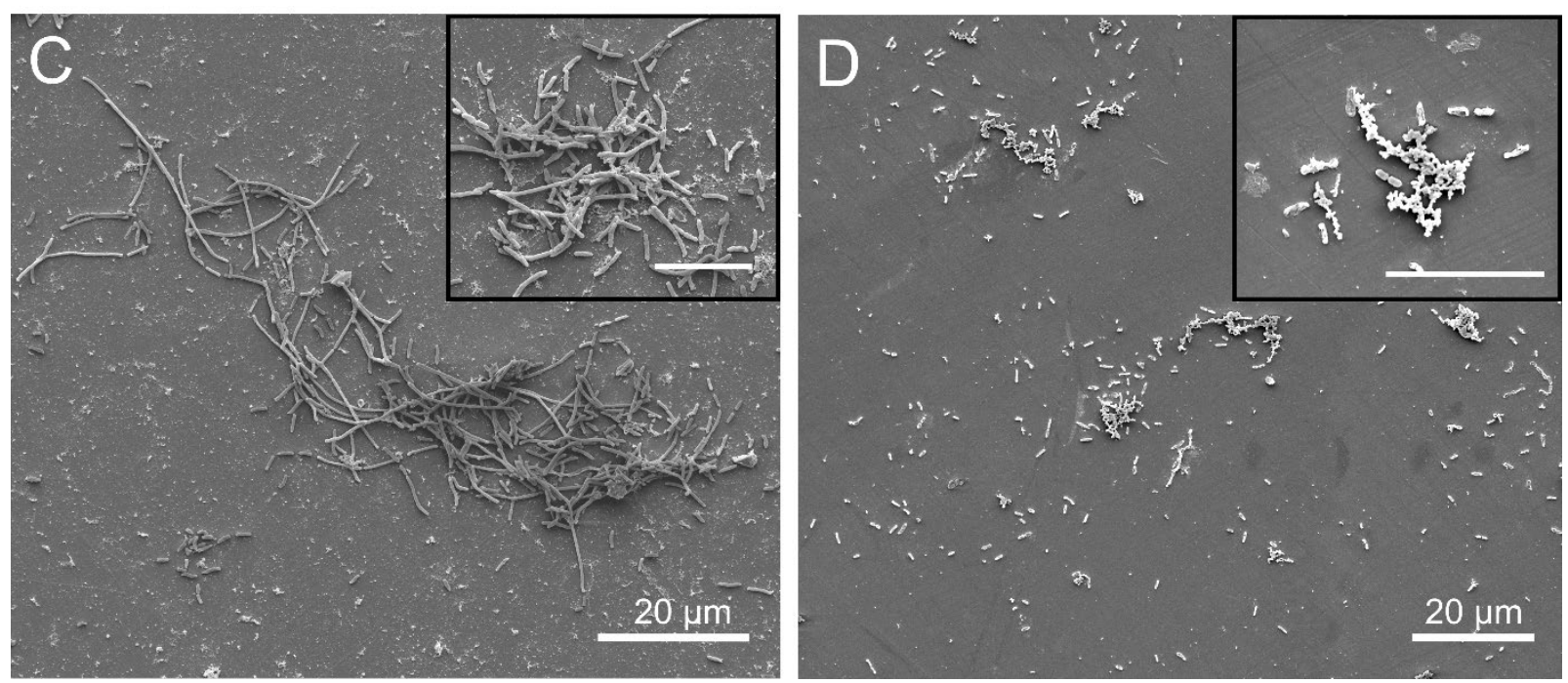

Figure 5. Scanning electron microscopy (SEM) images of a $P$. aeruginosa PAO1 biofilm grown for $24 \mathrm{~h}$ and $\mathrm{A}$ ) left without antibiotic treatment, B) treated with coated co-loaded ciprofloxacin hydrochloride (CIP) and colistin sulfate (COL) MCs, C) CIP MCs and D) COL MCs. Scale bars on the inserts are $10 \mu \mathrm{m}$. (2-column figure)

\subsection{Eradication of pre-formed $\boldsymbol{P}$. aeruginosa biofilms}

The combination of COL targeting the metabolically inactive subpopulations with CIP being active against the metabolically active subpopulation has been shown to enable eradication of $P$. aeruginosa biofilms in vitro (Pamp et al., 2008). As previously reported, MC-based delivery increased the local antibiotic concentration, thus improving eradication (Birk et al., 2020). In this study, we evaluated the effect of co-delivering CIP and COL in MCs on biofilm eradication. Before treatment, biofilms were grown for $72 \mathrm{~h}$ resulting in a biomass of $5.39 \pm 3.31 \mu \mathrm{m}^{3} / \mu \mathrm{m}^{2}(\mathrm{n}=43)$.

CIP:COL co-loaded in MCs worked significantly faster than CIP:COL in solution, as a much larger fraction of the biomass was found dead after $5 \mathrm{~h}(62.5 \pm 8.3 \%$ versus $10.6 \pm 10.1 \%, p \leq 0.0001)$, which is also evident from the confocal images (Figure 6). We believe this effect is due to the burst release of the antibiotics from the MCs (Figure 3) creating an immediate high local drug concentration and ultimately more dead biomass. After $24 \mathrm{~h}, 69.6 \pm 13.8 \%$ and $74.1 \pm 20.4 \%$ of dead biomass was found for CIP:COL in MCs and 
for CIP:COL in solution, respectively, showing no significant difference ( $p$-value of 0.4653). Interestingly, the biomass did not regrow after $24 \mathrm{~h}$, showing, that despite all drug being released within $30 \mathrm{~min}$ from the MCs, a long-lasting effect still applies. COL in MCs worked significantly faster than COL in solution $(56.3 \pm 12.3 \%$ versus $3.7 \pm 5.1 \%$ dead biomass after $5 \mathrm{~h}, \mathrm{p} \leq 0.0001$ ) (Supp. Materials, Figure S4). No regrowth occurred after $24 \mathrm{~h}$, and confocal images revealed dead biomass only in the core of the biofilm cluster. Notably, COL in MCs gave rise to a larger dead biomass than $\mathrm{COL}$ in solution $(56.8 \pm 17.4 \%$ versus $29.2 \pm 18.0 \%, p \leq 0.0001)$, which may indicate that less $\mathrm{COL}$ could be used to achieve the same bacterial killing. Treatment with CIP monotherapy for $5 \mathrm{~h}$ and $24 \mathrm{~h}$ resulted in a dead biomass of $14.1 \pm 10.8 \%$ and $81.9 \pm 9.8 \%$ with CIP in MCs and $26.8 \pm 13.9 \%$ and $85.8 \pm 10.5 \%$ with CIP in solution, showing no statistical difference ( $p \geq 0.05$, Supp. Materials, Figure S4) despite the local and sustained CIP release observed from the MCs. As evident from the confocal cross-section (Supp. Materials, Figure S4), CIP killed the bacteria in the periphery of the biofilm clusters. Previously, we reported that $88.2 \pm 5.3 \%$ of the biomass was killed, when exposing the biofilm to MCs loaded with about one-third of the CIP dose administered in the present study ( $120 \mu \mathrm{g}$ versus $336 \mu \mathrm{g}$ ) (Birk et al., 2020). This is very interesting, as no further improvement in the bacterial killing was found despite the increased concentration of CIP. This proves that CIP-loaded MCs are effective even with less antibiotic used. However, they are not able, despite increasing the dose, to eradicate the remaining fraction, which might be due to a dormant or resistant subpopulation not affected by CIP. To address this subpopulation, we aimed at delivering a synergistic CIP and COL therapy, but, as evident from the present study, no full biofilm eradication occurred neither with the solutions nor when confined in MCs.

Only few studies have been published employing drug delivery carriers for co-delivery of CIP and COL, and these all involve liposomes (Chai et al., 2019; Wang et al., 2018; Yu et al., 2020). This focus on liposomes is likely due to their biocompatibility combined with a unique property allowing fusion with bacterial phospholipid bilayers, whereby channels to release their antimicrobial cargo directly into the intracellular space of the bacterium are created (Forier et al., 2014). However, liposomes often suffer from a poor drug loading capacity, which is usually much lower than $10 \% \mathrm{w} / \mathrm{w}$ (Lee, 2020), and as a result, the quantity of drug is not sufficient to reach therapeutic levels in the body, or the amount of the carrier material required is too high which may cause undesirable side-effects (Couvreur, 2013). This is the first time that two synergistic antibiotics have been delivered in microfabricated devices such as MCs. The drug loading capacity of the applied MCs varied between 14.6-21.0 \% w/w, being considerably higher than loading values reported for liposomes. Our results clearly prove that the antibiotics confined in MCs works significantly faster than the antibiotic solutions. This shows the potential of the MCs in delivery of immediate high local concentrations of multiple antibiotics at the site of infection. Future studies will include a detailed investigation of the influence of varying antibiotic concentrations as well as treatment with antibiotics with other mechanisms of actions. Pamp et al. showed that a combined treatment with CIP and COL was able to kill almost all cells in a $P$. aeruginosa biofilm as less than $10 \mathrm{cell} / \mathrm{mL}$ survived the combinational treatment compared to $3.80 \times 10^{5}-2.25 \times 10^{7}$ 
cells $/ \mathrm{mL}$ on average in separately treated biofilm (Pamp et al., 2008). The concentrations of applied antibiotics were significantly higher than the concentrations applied in this study $(60 \mu \mathrm{g} / \mathrm{mL} \mathrm{CIP}$ and 25 $\mu \mathrm{g} / \mathrm{mL} \mathrm{COL}$ versus $4 \mu \mathrm{g} / \mathrm{mL} \mathrm{CIP}$ and $2.5 \mu \mathrm{g} / \mathrm{mL} \mathrm{COL}$ ) and a full eradication may therefore be achieved by increasing the drug concentrations. Moreover, to achieve full biofilm eradication other combinational strategies may be included such as incorporation of agents that degrade the extracellular matrix, promoting disruption of biofilms. Such a mechanism might promote phenotypical alterations making the otherwise tolerant dormant cells more susceptible.

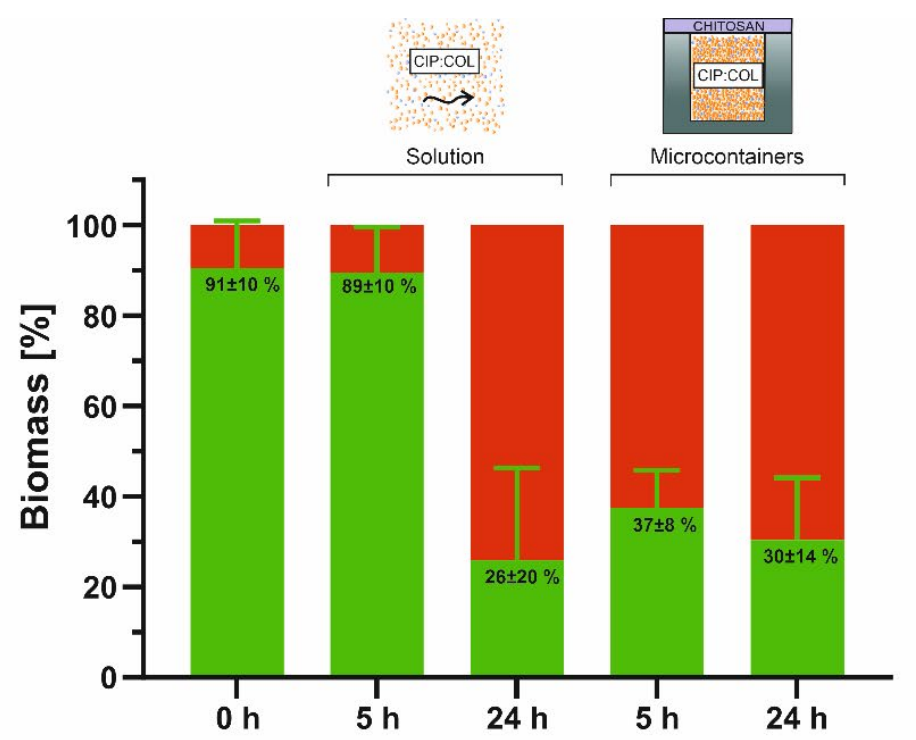

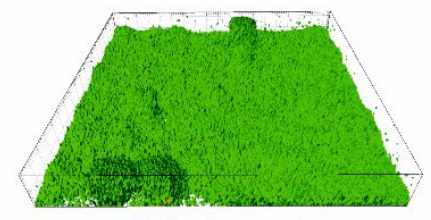

Before treatment
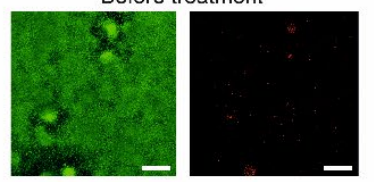

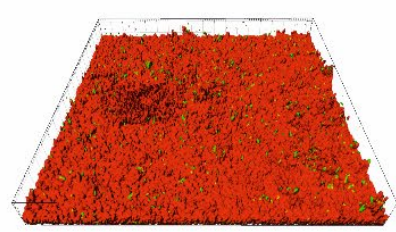

Microcontainers $5 \mathrm{~h}$
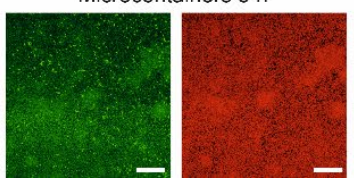

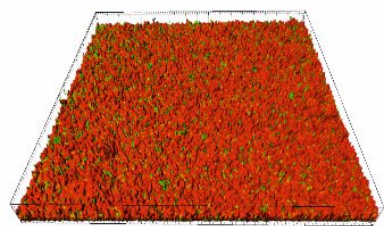

Microcontainers $24 \mathrm{~h}$
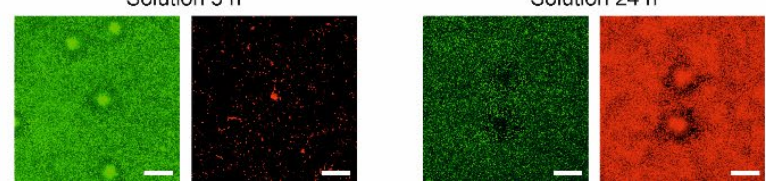

Figure 6. $72 \mathrm{~h}$ old $P$. aeruginosa (PAO1) biofilm treated with ciprofloxacin hydrochloride and colistin sulfate (CIP:COL) confined in MCs coated with chitosan or as a solution. Quantitative analysis of the biomass $\left(\mu \mathrm{m}^{3} / \mu \mathrm{m}^{2}\right)$ converted to the fraction of live/dead (\%) cells. Data is depicted as mean+SD ( $n=4-5$ biological replicates with 3-5 technical replicates for each type of treatment). Representative confocal laser scanning microscopy (CLSM) images of the biofilm before treatment, and 5 and $24 \mathrm{~h}$ post treatment with CIP:COL in MCs or as a solution. Green represents live bacteria and red shows dead bacteria. Scale bars: $30 \mu \mathrm{m}$. (2-column figure).

\section{Conclusion}

472 Previous studies utilizing MCs have primarily focused on delivery of single drug entities. In this study, we exploited the potential of co-delivery of two synergistic antibiotics, namely CIP and COL using MCs. We demonstrated that the activity of the antibiotics was retained while loaded in MCs. Combining CIP:COL 
the two antibiotics synergistically killed all subpopulations as no regrowth occurred. In contrast, full eradication could not be achieved when treating a $72 \mathrm{~h}$ old biofilm with MCs, yet the MCs worked significantly faster than the solution. These results show that the MCs have a great potential as delivery system for biofilm treatment by reaching immediate high local drug concentration of multiple drugs at the site of infection.

\section{Author contributions}

Conceptualization and methodology, S.E.B., C.M., H.K.J., J.A.J.H., S.M., L.H.N. and A.B.; supervision, S.E.B., C.M., J.A.J.H., S.M., L.H.N. and A.B; investigation, S.E.B., C.M., M.M.J., M.B.H.; resources, S.M. and A.B.; writing-original draft preparation, S.E.B.; writing-review and editing, all authors; funding acquisition, A.B. All authors have read and agreed to the published version of the manuscript.

\section{Supplementary material}

Supplementary material is available from Elsevier or from the author.

\section{Conflict of interest}

The authors declare no conflict of interest.

\section{Acknowledgements and funding}

The authors would like to acknowledge the Center for Intelligent Drug Delivery and Sensing Using Microcontainers and Nanomechanics (IDUN) whose research is funded by the Danish National Research Foundation (DNRF122) and Villum Foundation (Grant No. 9301). Micro- and nanofabrication specialist Lasse Højlund Eklund Thamdrup, DTU Health Tech is thanked for help with fabrication of the microcontainers. Furthermore, associate Professor Claus Sternberg, DTU Bioengineering is greatly acknowledged for providing access to the confocal scanning laser microscope. Helle Krogh Johansen was supported by The Novo Nordisk Foundation as a clinical research stipend (NNF120C1015920), by Rigshospitalets Rammebevilling 2015-17 (R88-A3537), by Lundbeckfonden (R167-2013-15229), by Novo Nordisk Fonden (NNF15OC0017444, NNF18OC0052776), by RegionH Rammebevilling (R144-A5287) and by Independent Research Fund Denmark/Medical and Health Sciences (FSS-4183-00051, DFF-903900037A). 


\section{References}

Abid, Z., Gundlach, C., Durucan, O., von Halling Laier, C., Nielsen, L.H., Boisen, A., Keller, S.S., 2017. Powder embossing method for selective loading of polymeric microcontainers with drug formulation. Microelectron. Eng. 171, 20-24. https://doi.org/10.1016/j.mee.2017.01.018

Ahmadi, F., Oveisi, Z., Samani, S.M., Amoozgar, Z., 2015. Chitosan based hydrogels: characteristics and pharmaceutical applications. Res. Pharm. Sci. 10, 1-16.

Ainslie, K.M., Lowe, R.D., Beaudette, T.T., Petty, L., Bachelder, E.M., Desai, T.A., 2009. Microfabricated Devices for Enhanced Bioadhesive Drug Delivery: Attachment to and Small-Molecule Release Through a Cell Monolayer Under Flow. Small 5, 2857-2863. https://doi.org/10.1002/smll.200901254

Aldred, K.J., Kerns, R.J., Osheroff, N., 2014. Mechanism of quinolone action and resistance. Biochemistry 53, 1565-1574. https://doi.org/10.1021/bi5000564

Anwar, H., Costerton, J.W., 1990. Enhanced activity of combination of tobramycin and piperacillin for eradication of sessile biofilm cells of Pseudomonas aeruginosa. Antimicrob. Agents Chemother. 34, 1666-1671. https://doi.org/10.1128/AAC.34.9.1666

Bergen, P.J., Bulitta, J.B., Forrest, A., Tsuji, B.T., Li, J., Nation, R.L., 2010. Pharmacokinetic/Pharmacodynamic Investigation of Colistin against Pseudomonas aeruginosa Using an In Vitro Model. Antimicrob. Agents Chemother. 54, 3783-3789. https://doi.org/10.1128/AAC.00903-09

Bialvaei, A.Z., Samadi Kafil, H., 2015. Colistin, mechanisms and prevalence of resistance. Curr. Med. Res. Opin. 31, 707-721. https://doi.org/10.1185/03007995.2015.1018989

Birk, S.E., Haagensen, J.A.J., Johansen, H.K., Molin, S., Nielsen, L.H., Boisen, A., 2020. Microcontainer Delivery of Antibiotic Improves Treatment of Pseudomonas aeruginosa Biofilms. Adv. Healthcare Mater. 9, 1901779. https://doi.org/10.1002/adhm.201901779

Bjarnsholt, T., 2011. Pseudomonas aeruginosa Biofilms in the Lungs of Cystic Fibrosis Patients, in: Moser, C., Jensen, P.Ø., Høiby, N. (Eds.), Biofilm Infections. Springer, pp. 167-185. https://doi.org/10.1007/978-1-4419-6084-9

Buyck, J.M., Tulkens, P.M., Van Bambeke, F., 2015. Activities of Antibiotic Combinations against Resistant Strains of Pseudomonas aeruginosa in a Model of Infected THP-1 Monocytes. Antimicrob. Agents Chemother. 59, 258-268. https://doi.org/10.1128/AAC.04011-14

Chai, G., Park, H., Yu, S., Zhou, F., Li, J., Xu, Q., Zhou, Q. (Tony), 2019. Evaluation of co-delivery of colistin and ciprofloxacin in liposomes using an in vitro human lung epithelial cell model. Int. J. Pharm. 569, 118616. https://doi.org/10.1016/j.ijpharm.2019.118616

Chirra, H.D., Shao, L., Ciaccio, N., Fox, C.B., Wade, J.M., Ma, A., Desai, T.A., 2014. Planar Microdevices for Enhanced In Vivo Retention and Oral Bioavailability of Poorly Permeable Drugs. Adv. Healthcare Mater. 3, 1648-1654. https://doi.org/10.1002/adhm.201300676

Ciofu, O., Tolker-Nielsen, T., 2019. Tolerance and Resistance of Pseudomonas aeruginosa Biofilms to Antimicrobial Agents-How P. aeruginosa Can Escape Antibiotics. Front. Microbiol. 10, 1-15. https://doi.org/10.3389/fmicb.2019.00913

Couvreur, P., 2013. Nanoparticles in drug delivery: Past, present and future. Adv. Drug Delivery Rev. 65, 21-23. https://doi.org/10.1016/j.addr.2012.04.010

Dalskov Mosgaard, M., Strindberg, S., Abid, Z., Singh Petersen, R., Højlund Eklund Thamdrup, L., Joukainen Andersen, A., Sylvest Keller, S., Müllertz, A., Hagner Nielsen, L., Boisen, A., 2019. Ex vivo 
intestinal perfusion model for investigating mucoadhesion of microcontainers. Int. J. Pharm. 570, 118658. https://doi.org/10.1016/j.ijpharm.2019.118658

Davies, J., Davies, D., 2010. Origins and Evolution of Antibiotic Resistance. Microbiol. Mol. Biol. Rev. 74, 417-433. https://doi.org/10.1128/MMBR.00016-10

Forier, K., Raemdonck, K., De Smedt, S.C., Demeester, J., Coenye, T., Braeckmans, K., 2014. Lipid and polymer nanoparticles for drug delivery to bacterial biofilms. J. Controlled Release 190, 607-623. https://doi.org/10.1016/j.jconrel.2014.03.055

Gao, W., Chen, Y., Zhang, Y., Zhang, Q., Zhang, L., 2018. Nanoparticle-based local antimicrobial drug delivery. Adv. Drug Delivery Rev. 127, 46-57. https://doi.org/10.1016/j.addr.2017.09.015

Giamarellos-Bourboulis, E.J., Sambatakou, H., Galani, I., Giamarellou, H., 2003. In Vitro Interaction of Colistin and Rifampin on Multidrug-Resistant Pseudomonas aeruginosa. J. Chemother. 15, 235238. https://doi.org/10.1179/joc.2003.15.3.235

Gunathilake, T.M.S.U., Ching, Y.C., Chuah, C.H., Illias, H.A., Ching, K.Y., Singh, R., Nai-Shang, L., 2018. Influence of a nonionic surfactant on curcumin delivery of nanocellulose reinforced chitosan hydrogel. Int. J. Biol. Macromol. 118, 1055-1064. https://doi.org/10.1016/j.ijbiomac.2018.06.147

Haagensen, J.A.J., Klausen, M., Ernst, R.K., Miller, S.I., Folkesson, A., Tolker-Nielsen, T., Molin, S., 2007. Differentiation and distribution of colistin- and sodium dodecyl sulfate-tolerant cells in Pseudomonas aeruginosa biofilms. J. Bacteriol. 189, 28-37. https://doi.org/10.1128/JB.00720-06

Hall-Stoodley, L., Costerton, J.W., Stoodley, P., 2004. Bacterial biofilms: from the Natural environment to infectious diseases. Nat. Rev. Microbiol. 2, 95-108. https://doi.org/10.1038/nrmicro821

Heydorn, A., Nielsen, A.T., Hentzer, M., Sternberg, C., Givskov, M., Ersbøll, B.K., Molin, S., 2000. Quantification of biofilm structures by the novel computer program comstat. Microbiology 146, 2395-2407. https://doi.org/10.1099/00221287-146-10-2395

Høiby, N., Bjarnsholt, T., Givskov, M., Molin, S., Ciofu, O., 2010. Antibiotic resistance of bacterial biofilms. Int. J. Antimicrob. Agents 35, 322-332. https://doi.org/10.1016/j.ijantimicag.2009.12.011

Holloway, B.W., Morgan, A.F., 1986. Genome Organization in Pseudomonas. Annu. Rev. Microbiol. 40, 79-105. https://doi.org/10.1146/annurev.mi.40.100186.000455

Jørgensen, J.R., Jepsen, M.L., Nielsen, L.H., Dufva, M., Nielsen, H.M., Rades, T., Boisen, A., Müllertz, A., 2019. Microcontainers for oral insulin delivery - In vitro studies of permeation enhancement. Eur. J. Pharm. Biopharm. 143, 98-105. https://doi.org/10.1016/j.ejpb.2019.08.011

Klausen, M., Heydorn, A., Ragas, P., Lambertsen, L., Aaes-Jørgensen, A., Molin, S., Tolker-Nielsen, T., 2003. Biofilm formation by Pseudomonas aeruginosa wild type, flagella and type IV pili mutants. Mol. Microbiol. 48, 1511-1524. https://doi.org/10.1046/j.1365-2958.2003.03525.x

Klockgether, J., Munder, A., Neugebauer, J., Davenport, C.F., Stanke, F., Larbig, K.D., Heeb, S., Schöck, U., Pohl, T.M., Wiehlmann, L., Tümmler, B., 2010. Genome Diversity of Pseudomonas aeruginosa PAO1 Laboratory Strains. J. Bacteriol. 192, 1113-1121. https://doi.org/10.1128/JB.01515-09

Lee, M.-K., 2020. Liposomes for Enhanced Bioavailability of Water-Insoluble Drugs: In Vivo Evidence and Recent Approaches. Pharmaceutics 12, 264. https://doi.org/10.3390/pharmaceutics12030264

Li, J., Nation, R., Turnidge, J., Milne, R., Coulthard, K., Rayner, C., Paterson, D., 2006. Colistin: the reemerging antibiotic for multidrug-resistant Gram-negative bacterial infections. Lancet Infect Dis 6, 589-601. https://doi.org/10.1016/S1473-3099(06)70580-1

Lin, L., Nonejuie, P., Munguia, J., Hollands, A., Olson, J., Dam, Q., Kumaraswamy, M., Rivera, H., Corriden, R., Rohde, M., Hensler, M.E., Burkart, M.D., Pogliano, J., Sakoulas, G., Nizet, V., 2015. Azithromycin 
Synergizes with Cationic Antimicrobial Peptides to Exert Bactericidal and Therapeutic Activity Against Highly Multidrug-Resistant Gram-Negative Bacterial Pathogens. EBioMedicine 2, 690-698. https://doi.org/10.1016/j.ebiom.2015.05.021

Liu, Y., Shi, L., Su, L., van der Mei, H.C., Jutte, P.C., Ren, Y., Busscher, H.J., 2019. Nanotechnology-based antimicrobials and delivery systems for biofilm-infection control. Chem. Soc. Rev. 48, 428-446. https://doi.org/10.1039/C7CS00807D

Mah, T.F.C., O’Toole, G.A., 2001. Mechanisms of biofilm resistance to antimicrobial agents. Trends Microbiol. 9, 34-39. https://doi.org/10.1016/S0966-842X(00)01913-2

Mazzoni, C., Jacobsen, R.D., Mortensen, J., Jørgensen, J.R., Vaut, L., Jacobsen, J., Gundlach, C., Müllertz, A., Nielsen, L.H., Boisen, A., 2019. Polymeric Lids for Microcontainers for Oral Protein Delivery. Macromol. Biosci. 19, 1900004. https://doi.org/10.1002/mabi.201900004

Mazzoni, C., Tentor, F., Strindberg, S.A., Nielsen, L.H., Keller, S.S., Alstrøm, T.S., Gundlach, C., Müllertz, A., Marizza, P., Boisen, A., 2017. From concept to in vivo testing: Microcontainers for oral drug delivery. J. Controlled Release 268, 343-351. https://doi.org/10.1016/j.jconrel.2017.10.013

Mohammed, M., Syeda, J., Wasan, K., Wasan, E., 2017. An Overview of Chitosan Nanoparticles and Its Application in Non-Parenteral Drug Delivery. Pharmaceutics 9, 53. https://doi.org/10.3390/pharmaceutics9040053

Mortensen, N.P., Fowlkes, J.D., Sullivan, C.J., Allison, D.P., Larsen, N.B., Molin, S., Doktycz, M.J., 2009. Effects of Colistin on Surface Ultrastructure and Nanomechanics of Pseudomonas aeruginosa Cells. Langmuir 25, 3728-3733. https://doi.org/10.1021/la803898g

Nation, R.L., Li, J., Cars, O., Couet, W., Dudley, M.N., Kaye, K.S., Mouton, J.W., Paterson, D.L., Tam, V.H., Theuretzbacher, U., Tsuji, B.T., Turnidge, J.D., 2015. Framework for optimisation of the clinical use of colistin and polymyxin B: the Prato polymyxin consensus. Lancet Infect. Dis. 15, 225-234. https://doi.org/10.1016/S1473-3099(14)70850-3

Nielsen, L.H., Keller, S.S., Boisen, A., 2018. Microfabricated devices for oral drug delivery. Lab Chip 18, 2348-2358. https://doi.org/10.1039/C8LC00408K

Nielsen, L.H., Keller, S.S., Gordon, K.C., Boisen, A., Rades, T., Müllertz, A., 2012. Spatial confinement can lead to increased stability of amorphous indomethacin. Eur. J. Pharm. Biopharm. 81, 418-425. https://doi.org/10.1016/j.ejpb.2012.03.017

Nielsen, L.H., Melero, A., Keller, S.S., Jacobsen, J., Garrigues, T., Rades, T., Müllertz, A., Boisen, A., 2016. Polymeric microcontainers improve oral bioavailability of furosemide. Int. J. Pharm. 504, 98-109. https://doi.org/10.1016/J.IJPHARM.2016.03.050

O’Neill, J., 2016. Tackling drug-resistant infections globally, Review on Antimicrobial Resistance. https://doi.org/10.4103/2045-080X.186181

Olivera, M.E., Manzo, R.H., Junginger, H.E., Midha, K.K., Shah, V.P., Stavchansky, S., Dressman, J.B., Barends, D.M., 2011. Biowaiver monographs for immediate release solid oral dosage forms: Ciprofloxacin hydrochloride. J. Pharm. Sci. 100, 22-33. https://doi.org/10.1002/jps.22259

Pamp, S.J., Gjermansen, M., Johansen, H.K., Tolker-Nielsen, T., 2008. Tolerance to the antimicrobial peptide colistin in Pseudomonas aeruginosa biofilms is linked to metabolically active cells, and depends on the pmr and mexAB-oprM genes. Mol. Microbiol. 68, 223-240. https://doi.org/10.1111/j.1365-2958.2008.06152.x

Parish, T., 2019. Steps to address anti-microbial drug resistance in today's drug discovery. Expert Opin. Drug Discov. 14, 91-94. https://doi.org/10.1080/17460441.2019.1550481 
Pastar, I., Nusbaum, A.G., Gil, J., Patel, S.B., Chen, J., Valdes, J., Stojadinovic, O., Plano, L.R., Tomic-Canic, M., Davis, S.C., 2013. Interactions of Methicillin Resistant Staphylococcus aureus USA300 and Pseudomonas aeruginosa in Polymicrobial Wound Infection. PLoS One 8, e56846. https://doi.org/10.1371/journal.pone.0056846

Patel, K.K., Tripathi, M., Pandey, N., Agrawal, A.K., Gade, S., Anjum, M.M., Tilak, R., Singh, S., 2019. Alginate lyase immobilized chitosan nanoparticles of ciprofloxacin for the improved antimicrobial activity against the biofilm associated mucoid $\mathrm{P}$. aeruginosa infection in cystic fibrosis. Int. J. Pharm. 563, 30-42. https://doi.org/10.1016/j.ijpharm.2019.03.051

Perinelli, D.R., Fagioli, L., Campana, R., Lam, J.K.W., Baffone, W., Palmieri, G.F., Casettari, L., Bonacucina, G., 2018. Chitosan-based nanosystems and their exploited antimicrobial activity. Eur. J. Pharm. Sci. 117, 8-20. https://doi.org/10.1016/j.ejps.2018.01.046

Ross, D.L., Riley, C.M., 1994. Dissociation and complexation of the fluoroquinolone antimicrobials - an update. J. Pharm. Biomed. Anal. 12, 1325-1331. https://doi.org/10.1016/0731-7085(94)00081-6

Schwerdt, M., Neumann, C., Schwartbeck, B., Kampmeier, S., Herzog, S., Görlich, D., Dübbers, A., GroßeOnnebrink, J., Kessler, C., Küster, P., Schültingkemper, H., Treffon, J., Peters, G., Kahl, B.C., 2018. Staphylococcus aureus in the airways of cystic fibrosis patients - A retrospective long-term study. Int. J. Med. Microbiol. 308, 631-639. https://doi.org/10.1016/j.ijmm.2018.02.003

Silva, F., Lourenço, O., Queiroz, J.A., Domingues, F.C., 2011. Bacteriostatic versus bactericidal activity of ciprofloxacin in Escherichia coli assessed by flow cytometry using a novel far-red dye. J. Antibiot. (Tokyo). 64, 321-325. https://doi.org/10.1038/ja.2011.5

Soares, A., Alexandre, K., Lamoureux, F., Lemée, L., Caron, F., Pestel-Caron, M., Etienne, M., 2019. Efficacy of a ciprofloxacin/amikacin combination against planktonic and biofilm cultures of susceptible and low-level resistant Pseudomonas aeruginosa. J. Antimicrob. Chemother. 74, 32523259. https://doi.org/10.1093/jac/dkz355

Stewart, P.S., 2002. Mechanisms of antibiotic resistance in bacterial biofilms. Int. J. Med. Microbiol. 292, 107-113. https://doi.org/10.1078/1438-4221-00196

Stover, C.K., Pham, X.Q., Erwin, A.L., Mizoguchi, S.D., Warrener, P., Hickey, M.J., Brinkman, F.S., Hufnagle, W.O., Kowalik, D.J., Lagrou, M., Garber, R.L., Goltry, L., Tolentino, E., WestbrockWadman, S., Yuan, Y., Brody, L.L., Coulter, S.N., Folger, K.R., Kas, A., Larbig, K., Lim, R., Smith, K., Spencer, D., Wong, G.K., Wu, Z., Paulsen, I.T., Reizer, J., Saier, M.H., Hancock, R.E., Lory, S., Olson, M. V, 2000. Complete genome sequence of Pseudomonas aeruginosa PAO1, an opportunistic pathogen. Nature 406, 959-64. https://doi.org/10.1038/35023079

Tamma, P.D., Cosgrove, S.E., Maragakis, L.L., 2012. Combination Therapy for Treatment of Infections with Gram-Negative Bacteria. Clin. Microbiol. Rev. 25, 450-470. https://doi.org/10.1128/CMR.05041-11

Tao, S.L., Popat, K., Desai, T.A., 2007. Off-wafer fabrication and surface modification of asymmetric 3D SU-8 microparticles. Nat. Protoc. 1, 3153-3158. https://doi.org/10.1038/nprot.2006.451

Tolker-Nielsen, T., Sternberg, C., 2011. Growing and analyzing biofilms in flow chambers. Curr. Protoc. Microbiol. 21, 1B.2.1-1B.2.17. https://doi.org/10.1002/9780471729259.mc01b02s21

Traugott, K.A., Echevarria, K., Maxwell, P., Green, K., Lewis, J.S., 2011. Monotherapy or Combination Therapy? The Pseudomonas aeruginosa Conundrum. Pharmacotherapy 31, 598-608. https://doi.org/10.1592/phco.31.6.598

Varanda, F., Pratas De Melo, M.J., Caço, A.I., Dohrn, R., Makrydaki, F.A., Voutsas, E., Tassios, D., Marrucho, I.M., 2006. Solubility of antibiotics in different solvents. 1. Hydrochloride forms of 
tetracycline, moxifloxacin, and ciprofloxacin. Ind. Eng. Chem. Res. 45, 6368-6374. https://doi.org/10.1021/ie060055v

Vorregaard, M., 2008. Comstat2 - A Modern 3D Image Analysis Environment for Biofilms. Technical University of Denmark, DTU.

Wallace, S.J., Li, J., Nation, R.L., Prankerd, R.J., Velkov, T., Boyd, B.J., 2010. Self-Assembly Behavior of Colistin and Its Prodrug Colistin Methanesulfonate: Implications for Solution Stability and Solubilization. J. Phys. Chem. B 114, 4836-4840. https://doi.org/10.1021/jp100458x

Wang, S., Yu, S., Lin, Y., Zou, P., Chai, G., Yu, H.H., Wickremasinghe, H., Shetty, N., Ling, J., Li, J., Zhou, Q., 2018. Co-Delivery of Ciprofloxacin and Colistin in Liposomal Formulations with Enhanced In Vitro Antimicrobial Activities against Multidrug Resistant Pseudomonas aeruginosa. Pharm. Res. 35, 187. https://doi.org/10.1007/s11095-018-2464-8

Wang, W., Zhou, Q.T., Sun, S.P., Denman, J.A., Gengenbach, T.R., Barraud, N., Rice, S.A., Li, J., Yang, M., Chan, H.K., 2016. Effects of Surface Composition on the Aerosolisation and Dissolution of Inhaled Antibiotic Combination Powders Consisting of Colistin and Rifampicin. AAPS J. 18, 372-384. https://doi.org/10.1208/s12248-015-9848-z

Weber, K., Delben, J., Bromage, T.G., Duarte, S., 2014. Comparison of SEM and VPSEM imaging techniques with respect to Streptococcus mutans biofilm topography. FEMS Microbiol. Lett. 350, 175-179. https://doi.org/10.1111/1574-6968.12334

Yu, S., Wang, S., Zou, P., Chai, G., Lin, Y.W., Velkov, T., Li, J., Pan, W., Zhou, Q.T., 2020. Inhalable liposomal powder formulations for co-delivery of synergistic ciprofloxacin and colistin against multi-drug resistant gram-negative lung infections. Int. J. Pharm. 575, 118915. https://doi.org/10.1016/j.ijpharm.2019.118915 